\title{
Studying a Series of Morphofunctional Index Values in Athletes of Reproductive age
}

\author{
Bugaevsky KA
}

Department of Medical and Biological Foundations of Sports and Physical Rehabilitation, the Petro Mohyla Black Sea State University, Nikolaev, Ukraine

Corresponding author: Konstantin Anatolyevich Bugaevsky, Assistant Professor, The Petro Mohyla Black Sea State University, Nikolaev, Ukraine.

Received date: September 27, 2021; Accepted date: October 27, 2021; Published date: November 04, 2021

Citation: Bugaevsky KA. (2021) Studying a Series of Morphofunctional Index Values in Athletes of Reproductive age. J. Women Health Care and Issues. 4(7); DOI:10.31579/2642-9756/088

Copyright: () 2021 Bugaevsky KA, This is an open access article distributed under the Creative Commons Attribution License, which permits unrestricted use, distribution, and reproduction in any medium, provided the original work is properly cited.

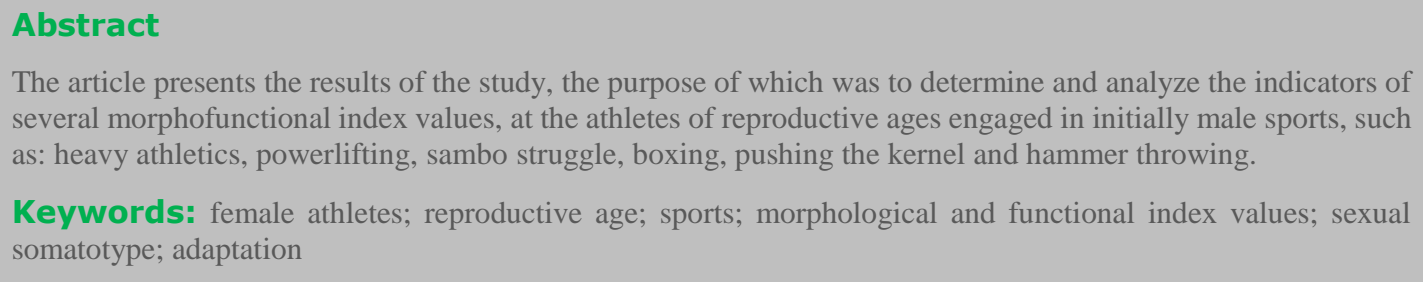

\section{Abbreviations}

- $\quad$ body mass index (BMI)

- $\quad$ pelvic index $(\mathbf{P I})$

- $\quad$ andromorphy index (AI)

- $\quad$ index masculinization (IM)

- $\quad$ sexual dimorphism index (SDI)

- $\quad$ Soloviev index (diameter of the wrist joint - SI)

- $\quad$ index of the relative width of the pelvis (IRWP)

- $\quad$ anatomically narrow pelvis (ANP)

- $\quad$ simple flat pelvis (SFP)

- $\quad$ general uniformly narrowed pelvis (GUNP)

- transversely narrowed pelvis (TNP)

\section{Introduction}

The modern female sport of higher achievements, requires female athletes of different age groups incredible, sometimes at the limit of their physical and psychological capabilities, to achieve the desired, victorious result. This applies to absolutely all modern sports, in which women athletes participate. Their participation in the original male sports, challenges their biology, anatomy and physiology, leading to adaptive inversions of their somatic sexual intercom, forced, compensatory for incredible physical and psychological loads, restructuring their body and psyche. The female body, artificially "triggered" into the male, under the influence of its own endocrine system, adaptively reducing the production of its estrogen, and increasing the products of androgens, which as a result, inevitably, by the forced adaptation, leads to their masculinization. The ovarian-menstrual cycle (OMC) of athletes is sacrificed, it is difficult, and sometimes excluding the function of fertility from the physiology of female athletes. All this is diminishing and leveling their biologically important female reproductive system. Restoration of the latter, after the athlete ceases actively, professionally, to play sports, often has many complications and obstacles, leading to the secondary infertility of the athlete, with the impossibility of independently get pregnant, preserve and endure the fetus [1]. Therefore, the study of medical and biological problems, and the issue of adaptive somatic rearrangements in athletes of reproductive age is very relevant and in demand.

The purpose of the study: to determine and analyze the indicators of some morphofunctional index values, in athletes of reproductive age engaged in initially male sports, such as: heavy athletics, powerlifting, sambo struggle, boxing, pushing the kernel and hammer throwing.

\section{Materials and research methods}

During the study, such methods as anthropometry were used, with the definition of the length and mass of the body of athletes, their shoulders width. Also, pelvimetry was carried out, with the definition of three latitudinal and two transverse sizes of the bone pelvis female athletes. Using the obtained results of anthropometric and pelvimetric measurements, a number of morphofunctional index values were determined, such as: body mass index (BMI); pelvic index (PI); andromorphy index (AI); index masculinization (IM); sexual dimorphism index (SDI); Soloviev index (diameter of the wrist joint - SI); index of the relative width of the pelvis (IRWP). Also, we used the method of literary-critical analysis of available sources of information, the method of mathematical statistics. The study involved 111 young athletes representing 6 sports, which can be conditionally referred to as 
primordially male. Representation by sports is as follows: weightlifting $(\mathrm{n}=21)$; powerlifting $(\mathrm{n}=19)$; sambo wrestling $(\mathrm{n}=22)$; boxing $(\mathrm{n}=18)$; shot put $(\mathrm{n}=16)$; hammer throw $(\mathrm{n}=15)$. The average age of young athletes was $23.47 \pm 1.23$ years. The experience of practicing these sports is from 5 to 12 years.

\section{Results of research and discussion.}

At the beginning of the study, we carried out the following anthropometric measurements, which were carried out according to the classical method: measuring the width of the shoulders, $\mathrm{cm}$; measurement of the width of the pelvis, or interspinous size (d. spinarum), cm; body length, $\mathrm{cm}$; body weight, $\mathrm{kg}$. Also, the outer dimensions of the bone pelvis (three transverse and two longitudinal) were determined. Measurement of the external dimensions of the bone pelvis (pelvimetry) was carried out using Martin's Pelvimeter, according to the classical technique adopted in anatomy and obstetrics $[2 ; 3 ; 4 ; 5]$. According to the results of the obtained anthropometric indicators, by means of mathematical recalculations, with strict consideration of the author's variants of the formulas, the necessary morphological and functional index values were calculated. The obtained anthropometric values, in each of the groups of athletes, are presented in the table. 1 , at $\mathrm{p}<0.05$ :

\begin{tabular}{|l|c|c|c|c|}
\hline \multicolumn{1}{|c|}{ Indicator name } & Shoulder width, cm & Pelvis width, $\mathrm{cm}$ & Body length, cm & Body mass, kg \\
\hline Weightlifting $(\mathrm{n}=21)$ & $40.08 \pm 1.06$ & $27.06 \pm 0.54$ & $178.34 \pm 1.01$ & $71.14 \pm 1.06$ \\
\hline Powerlifting $(\mathrm{n}=19)$ & $39.12 \pm 1.31$ & $27.19 \pm 1.03$ & $177.48 \pm 0.93$ & $71.32 \pm 1.11$ \\
\hline Sambo wrestling $(\mathrm{n}=22)$ & $38.55 \pm 1.87$ & $27.11 \pm 0.84$ & $175.76 \pm 1.16$ & $68.74 \pm 1.27$ \\
\hline Boxing $(\mathrm{n}=18)$ & $39.19 \pm 1.23$ & $27.53 \pm 0.53$ & $175.89 \pm 1.14$ & $67.58 \pm 1.23$ \\
\hline Shot put $(\mathrm{n}=16)$ & $40.13 \pm 1.06$ & $26.98 \pm 1.26$ & $178.56 \pm 1.24$ & $68.89 \pm 1.13$ \\
\hline Hammer throwing $(\mathrm{n}=15)$ & $40.65 \pm 1.08$ & $28.02 \pm 0.77$ & $177.12 \pm 0.63$ & $71.67 \pm 0.93$ \\
\hline
\end{tabular}

Table 1: Anthropometric indicators in the studied groups $(n=111)$

The analysis of the obtained anthropometric values showed that, according to the average group values, athletes in all six surveyed groups have wide shoulders and decreased indicators of the width of the pelvis (d. cristarum), which is normally $28-29 \mathrm{~cm}[2 ; 3 ; 4 ; 5]$. This means that the athletes in the surveyed groups have a male body type, which is one of the signs of the masculinization process taking place in their bodies. The ratio of body length and weight indicates the formation and proportionality of its component composition. The most powerful anthropometric indicators, in comparison with athletes of other groups, have young athletes involved in weightlifting, powerlifting and hammer throwing. These are quite strong athletes, with a masculine type of body shaping. After carrying out pelvimetry, the results of three longitudinal and two transverse, external dimensions of the bone pelvis were obtained in athletes, in each of the surveyed groups. The obtained results of pelvimetry are presented in a table. $2, \mathrm{p}<0.05$ :

\begin{tabular}{|l|c|c|c|c|c|}
\hline \multicolumn{1}{|c|}{ Indicator name } & d. spinarum, cm & d. cristarum, $\mathbf{c m}$ & d. trochante-rica, $\mathbf{c m}$ & c. externa, $\mathbf{c m}$ & $\mathbf{c .}$ vera, cm \\
\hline Weightlifting $(\mathrm{n}=21)$ & $24.13 \pm 0.47$ & $27.06 \pm 0.54$ & $30.73 \pm 0.63$ & $19.11 \pm 0.51$ & $10.37 \pm 0.11$ \\
\hline Powerlifting $(\mathrm{n}=19)$ & $24.37 \pm 0.33$ & $27.19 \pm 1.03$ & $31.17 \pm 0.88$ & $19.31 \pm 0.77$ & $10.23 \pm 0.66$ \\
\hline Sambo wrestling $(\mathrm{n}=22)$ & $24.81 \pm 0.27$ & $27.11 \pm 0.84$ & $31.02 \pm 0.61$ & $19.87 \pm 0.21$ & $10.45 \pm 0.49$ \\
\hline Boxing $(\mathrm{n}=18)$ & $25.01 \pm 0.24$ & $27.53 \pm 0.53$ & $30.15 \pm 0.74$ & $20.03 \pm 0.74$ & $10.89 \pm 0.67$ \\
\hline Shot put $(\mathrm{n}=16)$ & $24.63 \pm 0.97$ & $26.98 \pm 1.26$ & $31.18 \pm 0.39$ & $19.87 \pm 0.52$ & $10.78 \pm 0.71$ \\
\hline Hammer throwing $(\mathrm{n}=15)$ & $25.11 \pm 0.61$ & $28.02 \pm 0.77$ & $31.24 \pm 0.34$ & $20.12 \pm 0.21$ & $10.93 \pm 0.31$ \\
\hline
\end{tabular}

Table 2. Pelvimetric indicators in the studied groups $(n=111)$

The analysis of the obtained results of pelvimetry showed that the female athletes of all six examined groups have clinical manifestations of the anatomically narrow pelvis. This is convincingly evidenced by the reduced, in comparison with the normative, all the transverse and longitudinal dimensions of the bone pelvis. So, for example, d. spinarum, normally (for this age group), should correspond to $25-26 \mathrm{~cm}$; d. cristarum - 28-29 cm; d. trochanterica - 30-31 cm; c. externa - 20-21 cm; c. vera $11 \mathrm{~cm}[2 ; 3 ; 4 ; 5]$. The shape of these pelvis differs from the classic female ones, with the unfolded wings of the ilium. The pelvis of athletes in all groups engaged in primordially male sports tend to lengthen and contract, in accordance with the male, masculine forms of the bone pelvis. This adaptive process of changing sizes and shapes in athletes in athletic sports is forced and adaptive, in response to intense physical activity, during training and competitive processes. The results of calculating the indicators of a number of morphological and functional index values obtained in the studied groups of athletes are presented in table. 3, at $\mathrm{p}<0.05$ :

\begin{tabular}{|l|c|c|c|c|c|c|c|}
\hline \multirow{2}{*}{ Indicator name } & \multicolumn{7}{|c|}{ Results } \\
\cline { 2 - 8 } & BMI & RShWI & AI & IM & SDI & PI & SI \\
\hline Weightlifting $(\mathrm{n}=21)$ & $22.42 \pm 0.14$ & $15.39 \pm 0.17$ & $60.7 \pm 0.04$ & $1.49 \pm 0.17$ & $95.82 \pm 0.73$ & $86.06 \pm 0.13$ & $16.12 \pm 0.31$ \\
\hline Powerlifting $(\mathrm{n}=19)$ & $22.78 \pm 0.23$ & $15.82 \pm 0.24$ & $57,19 \pm 0,13$ & $1.43 \pm 0.11$ & $93.07 \pm 0.44$ & $87.72 \pm 0.23$ & $16.03 \pm 0.17$ \\
\hline $\begin{array}{l}\text { Sambo wrestling } \\
(\mathrm{n}=22)\end{array}$ & $22.37 \pm 0.31$ & $15.83 \pm 0.37$ & $58,0 \pm 0,32$ & $1.45 \pm 0.23$ & $93.31 \pm 0.32$ & $87.73 \pm 0.19$ & $15.83 \pm 0.33$ \\
\hline Boxing (n=18) & $21.98 \pm 0.19$ & $15.85 \pm 0.23$ & $59,48 \pm 0,16$ & $1.44 \pm 0.31$ & $93.2 \pm 0.14$ & $88.47 \pm 0.11$ & $15.76 \pm 0.11$ \\
\hline Shot put (n=16) & $21.68 \pm 0.22$ & $15.71 \pm 0.41$ & $60,43 \pm 0,21$ & $1.46 \pm 0.22$ & $95.43 \pm 0.38$ & $89.05 \pm 0.31$ & $16.18 \pm 0.37$ \\
\hline
\end{tabular}




\begin{tabular}{|l|l|l|l|l|l|l|l|}
\hline $\begin{array}{l}\text { Hammer throwing } \\
(\mathrm{n}=15)\end{array}$ & $22.98 \pm 0.28$ & $16.20 \pm 0.53$ & $62,03 \pm 0,19$ & $1.45 \pm 0.18$ & $96.4 \pm 0.56$ & $88.87 \pm 0.27$ & $16.34 \pm 0.37$ \\
\hline
\end{tabular}

Table 3: Indicators of morphological and functional index values in the studied groups $(n=111)$

The analysis of the results obtained for 7 morphological and functional index values, among the athletes of the studied groups, for a long time and professionally engaged in primordially male sports, is disappointing. Taking into account the average indicators for the groups, all of them have an anatomically narrow pelvis (ANP), with the advantage of a simple flat pelvis (SFP), a general uniformly narrowed (GUNP) and a transversely narrowed pelvis (TNP). The narrowing of the pelvis in female athletes is also confirmed by the indicators of the pelvic index (PI) and the index of the relative width of the pelvis (IRWP) $[6 ; 7 ; 8 ; 9]$. The indices of the andromorphy index (AI) and the masculinization index (MI), as well as the Solovyov index (SI), reliably confirm the significant severity of the adaptive processes of hyperandrogenism and somatic masculinization in athletes in all the examined groups $[6 ; 7 ; 8 ; 9]$. Also, the indicators of the sexual dimorphism index (SDI) are very convincing. According to the obtained values, in all groups of athletes, representatives of the physiological, gynecomorphic sexual somatotype are completely absent. There are only a few representatives of the transitional, mesomorphic sexual somatotype in groups where athletes are engaged in boxing and sambo wrestling. Dominant, in all groups, is pathological for women, inverse sexual somatotype $[6 ; 7 ; 8 ; 9]$.

\section{Conclusion}

1. It is estimated that athletes of reproductive age, long-term powerful, invoking by male sports, intensive adaptive somatic processes occur, leading to their masculinization.

2. Statistically reliably, all obtained indicators, a number of morphofunctional index values indicate the phenomena of adaptive masculinization and hyperandrogenism, inverse the original, basic femino state of the reproductive age female athletes.

3. It was reliably established that in all studied groups of athletes, there are also no representatives of the physiological, femino, gynechomorphic sexual samotype.

4. It was determined that the dominant sexual somatotype in all groups of female athletes is the inverse, andromorphic sex somatotype, revealed in $97.54 \%$ of all studied female athletes.

5. It was found that the remaining $2.46 \%$ of athletes have a transitional, mesomorphic sexual somatotype.

\section{References}

1. Oleinik E.A., Bugaevsky K.A. "Features of sex somatotypes and a number of anthropometric indicators in female athletes in paired female acrobatics". Chelovek. Sport. Medicina. [Human. Sport. Medicine], 2020, vol. 20, no. 2, pp. 22-28.

2. Gaivoronskiy IV et al. "Characteristics of pelviometric indices and substantiation of the effectiveness of their use for assessing the shape of the small pelvis in an adult woman". Journal of Obstetrics and Women's Diseases. 2005. Special issue V:98-102.

3. Yashvorskaya VA and Levitsky M.I. "On some anthropometric features of the pelvis in modern girls". Obstetrics and gynecology. 2012. 1:56-59.

4. Strelkovich, T.N., Medvedeva, N.I., \& Khapilina, E.A. "Anthropometric characteristics of the pelvis of women depending on the somatotype". In the world of scientific discoveries. 2(2). 2012: 60-73.

5. Vasilchishina AV et al. Morphometric parameters of the pelvis in the perinatal period of human ontogenesis. Morphology. 2016. Vol. 10. 3:67-70. - DOI 10.26641 / 1997-9665.2016.3.67-70

6. Martirosov E et al. Morphological characteristics of Wilt-Style Wrestlers. Vestnik Moscow University. Series 23: Anthropology. 2013. 2:63-85.

7. Nikityuk, D.B., Nikolenko, V.N., Klochkova, S.V., \& Minninbaev, T.Sh. Body mass index and other anthropometric indicators of physical status, taking into account age and individual typological characteristics of the constitution of women. Nutritional Issues. 4. 2015: 47-54.

8. Tkachuk, M.G., Oleinik, E.A., \& Dyusenova, A.A. Sports morphology: textbook. National State University of Physical Culture, Sports and Health named after P.F. Lesgaft, St. Petersburg. -SPb.: [b.i.]. 2019: 290 p.

9. Bakhareva NS., et al. Somatotypological characteristics in representatives of different age periods and its importance in sports orientation. Kuban Scientific Medical Bulletin, 25(6) 2018: 32-37.

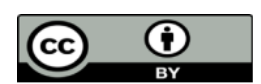

This work is licensed under Creative Commons Attribution 4.0 License

To Submit Your Article Click Here: Submit Manuscript

DOI: $10.31579 / 2642-9756 / 088$
Ready to submit your research? Choose Auctores and benefit from:

$>$ fast, convenient online submission

$>$ rigorous peer review by experienced research in your field

$>$ rapid publication on acceptance

$>$ authors retain copyrights

$>$ unique DOI for all articles

$>$ immediate, unrestricted online access

At Auctores, research is always in progress.

Learn more auctoresonline.org/journals/women-health-care-and-issues 